\title{
Desencontros entre uma prática crítica em psicologia e concepções tradicionais em educação
}

\author{
Ana Luísa de Marsillac Melsert \\ Pedro Paulo Gastalho de Bicalho
}

\begin{abstract}
Resumo
Com a inserção do trabalho de Análise do Vocacional em um curso pré-vestibular comunitário no Complexo da Maré, no Rio de Janeiro, produziuse um desencontro entre essa proposta da psicologia e as práticas educativas prevalentes nessa instituição, o que colocamos em análise neste artigo. Partindo do método cartográfico, método de pesquisa-intervenção, acompanhamos esses processos de desencontros a partir da realização de três grupos de Análise do Vocacional e da habitação de espaços coletivos na instituição. Recorrendo a uma análise sóciohistórica e política da constituição dos saberes da psicologia e da educação, percebemos que a Análise do Vocacional é uma prática crítica em psicologia, enquanto as concepções educativas predominantes no curso pré-vestibular na Maré reproduzem modelos tradicionais em educação. Esse desencontro, propomos, não diz respeito apenas a essa instituição, mas revela um modo de funcionamento presente em todo o sistema educacional brasileiro, ao qual o processo seletivo do vestibular dá visibilidade.
\end{abstract}

Palavras-chave: Orientação vocacional, educação, curso pré-vestibular.

\section{Mismatches between a critical practice in psychology and traditional views on education}

\begin{abstract}
In this paper we explore the inclusion of Vocational Analysis in a pre-university course in Complexo da Maré community, in Rio de Janeiro. We argue that there has been a mismatch between the proposal of psychology and educational practices prevalent in this institution. Based on the mapping method, method of intervention research, we follow these mismatch process, following the performance of three groups of Vocational Test and housing of collective spaces in the institution. Using a socio-historical and political constitution of knowledge of psychology and education, we realize that the analysis of the Vocation is a critical practice in psychology, while the educational concepts prevalent in the pre-university course in Maré reproduces traditional models in education. We claim that this mismatch reveals a mode of operating present throughout the Brazilian educational system, to which the selection process, vestibular, gives visibility
\end{abstract}

Keywords: Vocational guidance, education, pre-university.

\section{Desencuentros entre una práctica crítica en psicología y concepciones tradicionales en educación}

\begin{abstract}
Resumen
En este artículo se plantea el análisis de un desencuentro producido a partir de la inserción del trabajo de Análisis Vocacional en un curso preuniversitario comunitario en el Complexo de Maré, en Rio de Janeiro, cuya propuesta de psicología entra en desacuerdo con las prácticas educativas preponderantes en esa institución. Partiendo del método cartográfico, método de pesquisa-intervención, acompañamos estos procesos de desencuentros a partir de tres grupos de Análisis Vocacional realizados y de la habitación de espacios colectivos en la institución. Al valernos de un análisis socio-histórico y político de la constitución de los saberes de la psicología y de la educación notamos que el Análisis Vocacional es una práctica crítica en psicología mientras que concepciones educativas predominantes en el curso pre-universitario en Maré reproducen modelos tradicionales en educación. Se propone que este desencuentro no se relaciona apenas a esta institución, sino que revela un modo de funcionamiento presente en todo el sistema educacional brasileño, al cual el proceso selectivo de las pruebas de ingreso a las universidades da visibilidad.
\end{abstract}

Palabras clave: Análisis Vocacional, educación, pre-universitario. 


\section{Introdução}

Esta pesquisa surge a partir da reflexão sobre a inserção, em 2010, do trabalho de Análise do Vocacional (AV) em um curso pré-vestibular (CPV) comunitário localizado no complexo de favelas da Maré, no Rio de Janeiro. Foram realizados três grupos nessa instituição ao longo do ano, constituídos de alunos do curso pré-vestibular e de duas facilitadoras ${ }^{1}$, alunas de graduação integrantes do projeto de pesquisa-intervenção intitulado "Construindo um processo de escolhas mesmo quando 'escolher' não é um verbo disponível", inserido no Instituto de Psicologia da UFRJ desde 2006 como projeto de extensão². Em 2010, a proposta de Análise do Vocacional foi desenvolvida também em outro curso pré-vestibular comunitário e na Divisão de Psicologia Aplicada da UFRJ.

Ao introduzirmos a proposta da AV no pré-vestibular comunitário da Maré, percebemos que se produziu um desencontro entre, por um lado, as concepções educativas predominantes no discurso de alunos e professores e nas práticas prevalentes nessa instituição e, por outro, o trabalho da psicologia trazido pela AV e a visão que ela lança às questões educacionais. Essa observação nos suscitou muitas perguntas: Por que a proposta da Análise do Vocacional não estava sendo compreendida pelos diversos atores do curso pré-vestibular comunitário? Que referenciais em psicologia fundamentam a AV e qual a configuração das concepções educativas prevalentes no curso pré-vestibular comunitário? Como pensar o desencontro entre esses saberes e fazeres em psicologia e em educação?

Empreendemos a pesquisa que fundamenta este artigo na tentativa de responder a essas questões. É essencial ressaltar que, nesse processo de investigação, estamos norteados pelo referencial de que as ideias vigentes em um determinado momento são expressões das condições sociais, históricas e políticas daquele contexto específico, que forma certas visões de mundo. Assim, acreditamos que as representações do mundo devem ser entendidas não como algo cuja existência se sustenta em si, mas como um reflexo da forma como os homens se relacionam para produzir e reproduzir a vida em um determinado momento, concepção corroborada pelos autores dos quais nos valemos nessa pesquisa.

\footnotetext{
1 Por falta de um termo que melhor descreva tal atuação, permanecemos utilizando 'facilitador', mesmo não entendendo que o trabalho empreendido seja o de 'facilitar'. Termos como 'provocador' ou 'potencializador' poderiam ser também utilizados, mas tememos pela incompreensão do leitor.

2 Recorrendo a Bicalho e Sousa (2010), entendemos os projetos de extensão universitária, além da sua compreensão tradicional de que a universidade deve disseminar conhecimentos e cultura à população, bem como prestar serviços a ela. Sustentamos que os projetos de extensão devem ter função política de intervir na realidade concreta, voltando a universidade para as questões sociais e produzindo um conhecimento a partir das trocas estabelecidas entre a academia e a comunidade.
}

\section{O vestibular e as concepções tradicionais em educação}

Para Foucault, entre uma época histórica e outra, há uma mudança nas regras de construção de saberes ${ }^{3}$, delineando os discursos de verdade sustentados em determinado momento. Tais configurações emergentes de saber-poder produzem novas disciplinas, que formam novos domínios de objeto. Para entender como se configuraram as concepções tradicionais em educação e em psicologia, que sustentam o sistema do vestibular, precisamos compreender como, ao longo dos séculos XIX e XX, foram engendrados esses saberes e essas práticas.

A época moderna se caracteriza pela difusão do diagrama disciplinar de poder, que, como aponta Foucault (2008), comporta instrumentos, técnicas e procedimentos que "permitem o controle minucioso das operações do corpo, que realizam a sujeição constante de suas forças e lhes impõem uma relação de docilidade-utilidade" (p.118). Essa configuração, na modernidade, demanda a criação de mecanismos científico-disciplinares que tomem o homem como objeto de saber e de poder, pautando-se na tecnologia do exame, que submete o indivíduo ao controle de um saber permanente que avalia seus traços singulares, sua evolução, suas aptidões, suas capacidades. É nesse contexto que surgem a "a psicologia, que estudará o funcionamento da mente de normais e anormais; a pedagogia, que estudará o comportamento das crianças e suas formas de aprender, e outras disciplinas científicas inventadas como depósitos de saber legítimo para o estudo da vida e dos indivíduos" (Bacca, Pey, \& Sá, 2004, p. 33).

Patto (1996) nos mostra a relevância que tiveram, para a constituição das ciências humanas na modernidade, as ideias burguesas liberais, difundidas no século XIX, tendo como marcos a Revolução Francesa e a Revolução Industrial Inglesa. Esses movimentos engendraram mudanças políticas, sociais e econômicas profundas, com a consolidação do modo de produção capitalista que, contrapondo-se à ordem feudal, estabelece a centralidade dos direitos de cada indivíduo e traz a crença na construção de uma sociedade igualitária (Bock, 1999). Na realidade, no entanto, tais ideais se confrontavam com uma disparidade social radical. Afirma Patto (1996), nesse sentido: "Entre as pequenas conquistas de uma minoria do operariado e a acumulação de riqueza da alta burguesia, cavara-se um abismo que saltava aos olhos. Justificá-lo será a tarefa das ciências humanas que nascem e se oficializam neste período" (p.19).

Desse modo, a fim de justificar as diferenças sociais sem ferir a ideologia liberal - fundada na existência de direitos e oportunidades iguais para todos -, surgem as ciências

3 Os saberes, para Foucault, estão em um nível particular entre a opinião e o conhecimento científico. O saber ganha forma não apenas nas produções teóricas ou em instrumentos de experiência, mas em práticas e instituições. Comporta uma série de regras que caracterizam sua existência, sua história e seu funcionamento algumas regras peculiares a certo campo, outras a vários e, ainda, outras podem ser regras gerais para uma época (Bacca e cols., 2004). 
humanas. Fundados na noção de natureza humana, que determina que todos nascem com potencialidades que são desenvolvidas ao longo da vida, esses saberes afirmam as desigualdades entre os indivíduos em nossa sociedade como resultantes de méritos e esforços pessoais, tendo um papel ideológico ${ }^{4}$ de ocultar as determinações sócio-históricas e políticas das disparidades sociais (Bock, 1999). Nos campos da psicologia e da educação, tais ideias liberais alcançaram grande difusão no Brasil a partir dos anos 1920 e 1930, com a consolidação do movimento da Escola Nova, que, inspirado por princípios democráticos, fortaleceu a ideia de que os indivíduos têm potencialidades naturais, que deveriam ser avaliadas pela psicologia a fim de se distribuir as oportunidades de acordo com as aptidões de cada um (Antunes, 2005).

Esse pensamento de que o fracasso de uns e o sucesso de outros é resultado do potencial natural de cada um e de que o esforço pessoal é o único critério legítimo de seleção educacional e social se encontra até hoje profundamente enraizado nas concepções educacionais que vigoram em nosso país. A escolha do vestibular como sistema - aparentemente justo e imparcial - de acesso ao ensino superior, a partir da Reforma Universitária de 1968, está fundada nessa ideologia, que esconde os critérios perversos de seletividade socioeconômica que estão por trás das seletas listas de aprovados nas universidades, especialmente públicas, e de formados no ensino superior.

O vestibular, assumindo a tarefa de adequar a oferta de profissionais às necessidades do mercado de trabalho, consolidou-se como meio de seleção para o ensino superior, sofrendo pequenas alterações conjunturais desde então, mas mantendo sua estrutura. Com a progressiva expansão da educação superior no país desde os anos 1970 e o consequente aumento do número de vagas, difunde-se a ideia de que o acesso à universidade se democratizou e se tornou um meio de ascensão das classes pobres a estratos sociais mais ricos. Essa aparente democratização do ensino superior, no entanto, confronta-se com a realidade de que grande parcela de jovens das camadas pobres da sociedade continua excluída das universidades públicas, sem conseguir aprovação no vestibular, e das privadas, por não conseguir manter os elevados custos de mensalidades, situação que levou à criação de políticas públicas, nos anos 2000, para minorar essas disparidades no acesso à universidade ${ }^{5}$.

A noção de capital cultural de Bourdieu, que, como indica Swartz (1997), diz respeito a competências sociais e linguísticas socialmente herdadas, aponta para o fato de que o vestibular, ao exigir o domínio de conteúdos e de uma lin-

4 A ideologia, para Bock (1999), é a forma ilusória pela qual se representa o real, sendo um "instrumento que oculta as diferenças e desigualdades ao construir uma rede imaginária de ideias e valores que possuem base real, mas construída de maneira invertida", tomando os resultados do processo como sua causa (p. 26).

5 Foram implementadas, em diversas universidades públicas, políticas afirmativas de cotas socioeconômicas, assim como políticas de financiamento nas particulares, por meio do Programa Universidade para Todos (Prouni), que oferece bolsas integrais e parciais aos alunos de acordo com critérios econômicos e sociais. guagem ligados às camadas mais ricas da sociedade, é um sistema injusto e parcial, que privilegia aqueles cuja constituição subjetiva foi atravessada pelos modos de vida das elites socioeconômicas. Como os sucessos e os fracassos no vestibular, interpretados à luz da ideologia meritocrática, devem-se ao talento e/ou ao esforço pessoal, cada educando aceita como natural a sua situação particular, vangloriando-se por seu sucesso ou se culpando por seu fracasso, sem compreender os múltiplos determinantes históricos, políticos e sociais envolvidos nesses processos.

\section{A Análise do Vocacional: uma prática crítica em psicologia}

Já observamos, com o auxílio de Foucault, que as mudanças nas configurações sócio-históricas e políticas nas relações de saber-poder de uma época para a outra engendram contextos que possibilitam a emergência de saberes com características afins. Assim é com a psicologia e com a educação, campos que estão historicamente imbricados. Se a modernidade constitui um campo de forças que leva à configuração da psicologia e da educação como saberes científicos disciplinares, fundando práticas e teorias tradicionais, na década de 1980, com a abertura político-democrática do Brasil, é constituído um panorama sócio-histórico e político favorável ao crescimento do movimento crítico sustentado por alguns psicólogos e educadores desde os anos 1960. Esses saberes e fazeres críticos se distanciam das tendências individualizantes que prevaleciam até então na psicologia e na educação, afirmando seus papéis políticos e seus compromissos éticos e sociais, nos campos da profissão e da produção científica.

A Análise do Vocacional (AV) se alinha a esse movimento instituinte de abertura para novos possíveis em educação e em psicologia. Inspirada nas práticas institucionalistas, que têm como referencial a Análise Institucional Francesa, a AV se afirma como um modo diferente de se pensar a escolha profissional, tomando-a como analisador ${ }^{6}$ a partir do qual se lança luz sobre os critérios que o sujeito usa para escolher nos diferentes âmbitos da vida, em uma aposta que pretende fortalecer a autonomia dos participantes (Frotté, 2001).

A proposta da Análise do Vocacional parte da compreensão de que a subjetividade é essencialmente fabricada e modelada no registro do social, como sustentam Guattari e Rolnik (1996). Não é passível, assim, de totalização ou centralização no indivíduo, mas de um entrecruzamento de atravessamentos coletivos, não só sociais, mas também econômicos, tecnológicos, midiáticos. O processo de produção de escolhas, nesse sentido, nada mais é do que

6 Noção definida por Rodrigues e Souza (citado por Aguiar \& Rocha, 2007) como "acontecimento, indivíduo, prática ou dispositivo que revela, em seu próprio funcionamento, o impensado de uma estrutura social - tanto a não conformidade com o instituído como a natureza desse mesmo instituído" (p. 656). 
um processo de produção de subjetividade, um fenômeno complexo, em que várias forças se entrecruzam.

Partindo dessa concepção, a proposta de Análise do Vocacional sustenta que não temos uma essência a priori e nem uma vocação natural que devem ser desveladas, e sim somos constituídos nos atravessamentos de múltiplas forças ao longo da vida. Como mostram Bicalho, Bartalini e Sasso (2010), a AV se distancia dos paradigmas estatístico e clínico que norteiam as atuações tradicionais em orientação vocacional e buscam desvelar a essência do sujeito para adequá- la a uma vocação - entendida, nesses referenciais, como o lugar adequado para cada indivíduo ou, ainda, como dom, talento, aptidão. Em sentido diverso, para a AV, a construção do vínculo profissional é feita a partir de experimentações de um campo de possibilidades durante toda a existência, em um processo contínuo e criativo de construção e de desconstrução subjetiva, como aponta Mansano (2003).

Para lançar luz a esses movimentos de construção de mundos, o trabalho de AV se utiliza de dispositivos, que, segundo Deleuze (1996), fazendo uma leitura de Foucault, são máquinas de fazer ver e de fazer falar, que dão visibilidade a modos naturalizados de existência e maneiras instituídas de ser, de pensar e de estar no mundo. Os dispositivos usados no trabalho de Análise do Vocacional são múltiplos - textos, músicas, jogos, por exemplo - e elaborados em um processo sempre contínuo de criação de dinâmicas, elaboradas de acordo com as demandas que surgem nos encontros precedentes, em um movimento sempre inventivo.

É importante mencionar que a Análise do Vocacional é uma proposta desenvolvida sempre em grupos, dispositivo que, a partir do encontro de vários sujeitos, faz ver e faz falar múltiplas formas de ser, de pensar, de experimentar, de sentir o mundo. Esse encontro com a diferença tem o potencial de fazer emergir o estranhamento de referenciais naturalizados, dando visibilidade ao que escapa dos processos de produção de subjetividade hegemônicos. Nesse ponto, destacamos que o trabalho com grupos é sempre uma aposta: não sabemos de antemão que efeitos produzirá (Barros, 2007).

Ressaltamos, neste ponto, que, ao nos referirmos aos grupos de Análise do Vocacional, não estamos falando apenas das pessoas que se inscrevem para realizar esse trabalho, mas também dos então chamados facilitadores. Contrariando as relações de poder instauradas em práticas tradicionais em psicologia e em educação, na AV os facilitadores se reconhecem em sua não neutralidade, percebendo como afetam o grupo e como são afetados por ele. Colocando-se em uma relação horizontal com os demais participantes do grupo, os facilitadores se propõem a fazer o sujeito se haver com seus processos de escolha, sem aceitar o lugar de especialistas que têm conhecimento sobre o outro ou o poder de dizer algo sobre ele.

A Análise do Vocacional, portanto, difere de propostas tradicionais em psicologia e em educação ao se afirmar como uma prática política, que, como propõe Maciel Junior (2005), é aquela que visa produzir novos modos de subjeti- vação e problematizar os lugares instituídos. Aposta, assim, na produção de diferenças e atua no sentido de possibilitar que o sujeito se interrogue sobre a sua forma de estar no mundo e, consequentemente, sobre a realidade em que vive.

\section{Método}

Escolhemos, para sustentar o trabalho de Análise do Vocacional que realizamos no curso pré-vestibular na Maré, o método da cartografia, que, nas palavras de Barros e Kastrup (2009), é um método de pesquisa-intervenção em que se acompanham processos de produção de subjetividade que estão em curso. O método cartográfico afirma que o conhecer e o fazer, o intervir e o pesquisar são indissociáveis e que toda pesquisa é intervenção, uma vez que o percurso da investigação produz efeitos sobre o objeto, sobre o pesquisador e sobre a produção de conhecimento, que devem ser acompanhados e colocados em análise. Desse modo, o ato de pesquisar não é orientado por metas ou saberes que se estabelecem anteriormente sobre a realidade pesquisada, assim como não busca representar um objeto separado do sujeito que pesquisa.

Diferente do método da ciência moderna, a cartografia não visa isolar o objeto de suas articulações históricas nem de suas conexões com o mundo. Ao contrário, o objetivo da cartografia é justamente desenhar a rede de forças à qual o objeto ou fenômeno em questão se encontra conectado, dando conta de suas modulações e de seu movimento permanente. (Barros \& Kastrup, 2009, p. 57)

Informados por esse referencial teórico-metodológico, habitamos, durante o ano de 2010, o espaço do curso pré-vestibular comunitário na Maré, do qual não participávamos, o que abriu a possibilidade de fazer ver e conhecer um funcionamento institucional que foi se produzindo ao longo de nossa permanência no CPV. Valendo-nos do método da cartografia, procuramos nos abrir aos encontros, sem procurar algo que já havia na instituição antes de nos inserirmos nela.

Ao longo dos nove meses que permanecemos no curso pré-vestibular comunitário durante o ano de 2010, fomos sentindo o desencontro entre a psicologia proposta pela Análise do Vocacional e as concepções educativas predominantes no curso pré-vestibular comunitário a partir das trocas que realizamos com múltiplos sujeitos, em diversos espaços: nas reuniões com o corpo docente e a direção do CPV, nos três grupos de AV que realizamos - e dos quais participaram, até o final, 15 sujeitos -, nos espaços de interação social na instituição, na Assembleia de Alunos. Usamos como dados para esta pesquisa também os diários de campo produzidos durante a permanência na instituição, bem como os laudos psicológicos com caráter problematizador que produzimos para cada participante ao final dos grupos de AV. 


\section{Resultados e Discussão}

\section{O curso pré-vestibular comunitário na Maré e as concepções tradicionais, disciplinares em educação}

No curso pré-vestibular comunitário na Maré em que inserimos a proposta de Análise do Vocacional percebemos, frequentemente, como a ideologia da ascensão pelo esforço pessoal está presente nas representações sobre o sistema educacional brasileiro. Embora haja na instituição a percepção da desigualdade social no acesso à universidade, afirmada pela própria criação de cursos pré-vestibular na comunidade, a disparidade socioeconômica no acesso à universidade não é atribuída, na fala de muitos alunos e professores, ao sistema de seleção ou aos ideais que o sustentam, e sim justificada pela má qualidade das escolas públicas - que não ensinariam os conteúdos exigidos no vestibular - face às particulares. O sistema meritocrático de seleção para as escassas vagas no ensino superior é, assim, naturalizado, encobrindo os processos de seletividade socioeconômica que estão por trás do afunilamento no ingresso às universidades no Brasil ${ }^{7}$.

Percebemos também que o curso pré-vestibular em que trabalhamos reproduz a ideologia do mérito e do esforço pessoal nas relações dentro da própria instituição, classificando e hierarquizando os alunos de acordo com o seu desempenho - escolar e comportamental. Foucault (2008) fala da disciplina exercida em instituições educacionais, que distribuem os corpos em séries, filas e classificações, provocando distanciamentos que separam os indivíduos e levam a uma hierarquização do saber e das capacidades, dos valores e dos méritos. Os comportamentos e desempenhos passam a ser classificados em polos positivos ou negativos, como, por exemplo, bom ou mau comportamento, boas ou más notas. Essa determinação de lugares para cada sujeito possibilita o controle de cada um e o trabalho simultâneo de todos.

No curso pré-vestibular em que nos inserirmos, observamos, nessa direção, o enquadramento dos alunos em uma série de categorizações quanto às suas notas e aos seus comportamentos. A realização de simulados cujos resultados ficam expostos em um mural, em uma tabela organizada por nomes, mas implicitamente hierarquizada por notas, exemplifica isso. No mesmo sentido, observamos no discurso dos professores nas reuniões da equipe do CPV que eles construíam hierarquias entre as quatro turmas do curso, em que ocupavam os estratos mais altos as classes que eram "participativas" e "comportadas", enquanto eram consideradas as piores aquelas turmas em que os alunos conversavam, "não colaboravam", "não queriam nada com a vida", faltavam a muitas aulas. A mesma classificação valia para os alunos, em um nível individual. A nós, que represen-

7 Bock (2010), em um estudo sobre orientação profissional para classes pobres, observou, em sentido convergente, a naturalização do vestibular como processo de seleção para a universidade no discurso dos jovens com que trabalhou. távamos a psicologia com o trabalho de Análise do Vocacional, eram muitas vezes direcionados, pelos professores e coordenadores, os estudantes que ocupavam os graus mais baixos na categorização instituída pela equipe do CPV, com a demanda de ajustá-los, de direcioná-los - de, em resumo, discipliná-los e normatizá-los, pedido que colocamos em análise, mas não aceitamos.

Guattari e Rolnik (1996) nos ajudam a entender esse processo de normatização dos sujeitos-alunos que observamos no CPV, ao trazerem a ideia de que há uma produção de subjetividade serializada no contexto do Capitalismo Mundial Integrado, em que a tendência é igualar tudo através de grandes categorias unificadoras e redutoras, impedindo a emergência de processos de singularização ${ }^{8}$. Essa linha de montagem subjetiva é sustentada por funções como a culpabilização, exercida a partir da proposição de uma imagem de referência diante da qual os sujeitos se sentem insuficientes, e a infantilização, em que deixamos que outros pensem e organizem por nós a produção e a vida social.

No curso pré-vestibular do qual estamos tratando, presenciamos um processo de culpabilização dos alunos por meio da difusão de um modelo de estudante exemplar: aquele que não falta às aulas e que "valoriza a oportunidade" que lhe é dada de ingressar em um curso pré-vestibular na comunidade, representação que revela uma concepção assistencialista da função da instituição - nos grupos de Análise do Vocacional, eram recorrentes discursos dos estudantes se culpando por não estudar e não se dedicar ao CPV tanto "quanto deveriam". Assistimos a uma infantilização dos estudantes revelada na demanda oferecida à psicologia de ajudar os alunos "perdidos" a organizar seus projetos de vida. Observamos a imposição de normas de presença rígidas, com o estabelecimento da frequência nas aulas como critério de modulação do comportamento dos estudantes: as concorridas aulas-campo no Rio de Janeiro e em viagens mais longas a outras cidades são recompensas dadas àqueles alunos que comparecem mais às aulas.

Lembrando Foucault (2008), deparamo-nos, na instituição educacional, com um mecanismo disciplinar em ação, atuando de modo a reduzir os desvios, em um sistema corretivo que sanciona os comportamentos indesejáveis e gratifica os esperados - "boas" notas, a "boa" frequência, "bom" comportamento. Desse modo, percebemos em que medida o curso pré-vestibular em que trabalhamos alinha-se à ideologia meritocrática que prevalece no sistema de educacional brasileiro, não só reproduzindo, como também reforçando a ideologia do esforço pessoal. Os mesmos processos podem ser observados nas demais instituições que preparam para o vestibular, públicas e comunitárias, que, apesar de não integrarem o sistema educacional formal brasileiro, revelam seu modo de funcionamento e as ideologias que o sustentam.

8 Para Guattari e Rolnik (1996), trata-se dos movimentos de protesto do inconsciente contra as formas de subjetivação serializadas engendradas na sociedade capitalística, através da afirmação de outras maneiras de ser e estar no mundo. 


\section{A inserção da proposta da Análise do Vocacional no curso pré-vestibular na Maré: reflexões sobre um desencontro}

O afastamento da Análise do Vocacional em relação aos paradigmas dominantes nos campos da educação e da psicologia ficou evidente em sua inserção no curso pré-vestibular comunitário na Maré. Sempre que explicávamos a nossa proposta, percebíamos que ela não estava sendo assimilada pela maioria dos professores e funcionários da instituição - é importante ressaltar que algumas pessoas da equipe se identificaram com o nosso trabalho e acreditaram em sua potência. O mesmo ocorreu com os alunos, no início do trabalho; no entanto, ao passar pelo processo de AV nos grupos, eles entenderam a proposta e a experimentaram de forma intensa e afetiva, o que levou alguns participantes dos primeiros grupos que realizamos na instituição a querer repetir a experiência no segundo semestre.

Uma interrogação interessante que nos acompanhou em nossa permanência nessa instituição foi a tentativa de entender o processo de evasão dos grupos de AV e as frequentes faltas de alguns integrantes aos encontros. Sem entrar na questão da evasão que ocorre em cursos pré-vestibular comunitários - o que demandaria outro (complexo) trabalho de pesquisa -, propomos que esse processo nos grupos de Análise do Vocacional pode estar ligado à liberdade que caracteriza essa proposta, que não exige presença dos participantes, embora trabalhe com a noção de responsabilidade na escolha de integrar o grupo. Por não reproduzir a lógica do curso pré-vestibular, em que a frequência é controlada em mecanismos de culpabilização e incentivada por meio de recompensas, a proposta de AV trabalha com a autonomia dos participantes, que, fora desse mecanismo de imposição de presença, podem escolher deixar de participar do trabalho ou faltar.

Desse modo, a Análise do Vocacional busca problematizar quem são esses sujeitos que escapam dos modos de subjetivação hegemônicos estabelecidos dentro da instituição e o que se faz com essas subjetividades que não se adaptam aos padrões de "bons" alunos, de estudantes "normais" - é sempre interessante pensar na etimologia da palavra "normal", que vem de norma, regra, padrão, indicando a adequação a uma média. $\mathrm{O}$ que fazer com aqueles que escapam às regras estabelecidas e cumpridas pela maioria? É importante compreender que esses sujeitos que fogem às formas de subjetivação instituídas podem estar expressando, de sua forma, a resistência a esse processo de captura de subjetividades, em uma busca pela autonomia, em uma tentativa de criar as próprias regras, de procurar formas autênticas de existir.

Neste ponto, faz-se relevante pensar sobre a função política das instituições educativas como promotoras de mudanças e criadoras de possibilidades para a emergência de modos de subjetivação singulares, inéditos. No curso pré-vestibular na Maré, observamos que, mesmo que em uma reunião de equipe seus coordenadores tenham manifestado um desejo de resgatar a dimensão de formação política do CPV, essa proposta pareceu apenas uma ideia vaga, solta no ar, adotada por alguns professores de forma individual, mas sem haver um movimento coletivo nessa direção. Destacamos que, ao final do ano, percebemos uma convergência entre nossas observações e a percepção da equipe diretiva do CPV, que propôs uma reformulação no funcionamento institucional para 2011, visando resgatar a função política das práticas educativas realizadas no curso pré-vestibular.

No mesmo sentido, o trabalho de Análise do Vocacional aposta na função política dos cursos pré-vestibular como lugares de produção - e não apenas reprodução - de conhecimentos. Apostamos que o nosso trabalho alarga as possibilidades de se pensar e viver o momento do vestibular, para além da finalidade de aprovação, buscando disparar um movimento de produção de novos possíveis não só na escoIha da profissão, como também nos demais campos da vida dos sujeitos. Ao nos inserir em espaços educativos comunitários, pretendemos disparar um processo de abertura de possibilidades de escolhas para uma população que tem as escolhas limitadas para ela - como afirma o nome do projeto em que a AV se insere, "Construindo um processo de escoIhas mesmo quando 'escolher' não é um verbo disponível".

Em convergência a essas apostas, observamos que o trabalho de Análise do Vocacional que realizamos no CPV na Maré foi disparador de mudanças nos sujeitos que participaram do processo - tanto os alunos do curso quanto as facilitadoras. A partir da experiência nos grupos, em que surgiram discussões não só sobre a escolha da profissão, como também sobre o sistema educacional brasileiro e as disparidades sociais, observamos que os participantes da AV experimentamos - concordância proposital por silepse processos de mudança, colocando nossas visões de mundo em análise a partir do encontro com as diferentes maneiras de perceber a vida. Destacamos, nesse ponto, a relevância que adquiriu, em um dos grupos, no qual as disparidades sociais surgiram como disparadores potentes, o fato de as facilitadoras não morarem na Maré, o que abriu espaço para o estranhamento de concepções naturalizadas sobre as diferenças entre as classes que compõem a nossa hierarquizada sociedade.

\section{Considerações finais}

Em uma proposta coerente com as concepções críticas no campo da psicologia e da educação, apresentamos considerações não definitivas acerca de nossa investigação sobre o porquê do desencontro entre a proposta da Análise do Vocacional e as concepções educativas presentes no curso pré-vestibular comunitário em que inserirmos esse trabalho. Tal caráter provisório se deve ao fato de acreditarmos que o que pensamos, sentimos, fazemos, escolhemos está sempre sendo atravessado por novas forças, que reconfiguram o estado anterior e nos impulsionam para o novo.

Norteados por esse referencial, propomos que tal desencontro que observamos se deve ao fato de que a Aná- 
lise do Vocacional se encontra em um registro de teorias-práticas críticas, ao passo que o vestibular está fundado em concepções tradicionais, disciplinares e meritocráticas em educação, reproduzidas pelos cursos preparatórios para esses exames. Apesar de estarmos inseridos, com o trabalho de $\mathrm{AV}$, em uma instituição comunitária, não sentimos diferenças significativas no seu modo de funcionamento em relação ao modelo de cursos pré-vestibulares particulares, que classificam, segregam e hierarquizam alunos em nome do objetivo final de aprovar o maior número possível de candidatos para apresentar no mural, na internet, no jornal, no outdoor, provando o "sucesso" do curso pré-vestibular - e perguntamo-nos: sucesso pessoal dos alunos? Mérito da instituição? Vitória de uma classe social? Prevalência de uma ideologia investida de poder político, econômico, social? Sem entender que as vitórias não são individuais, e sim coletivas, os jovens aprovados no vestibular reforçam a ideia de que mereceram as suas vagas e as obtiveram somente por esforço pessoal.

Percebemos que, no curso pré-vestibular comunitário em que trabalhamos na Maré, como nos particulares, os professores ensinam - se as propostas de mudanças na instituição se concretizarem, poderemos usar o verbo no passado - seus conteúdos de forma desconectada da vida, depositando nos alunos um imenso arsenal de informações, que eles tentam memorizar em uma maratona frenética de estudos que, se não resulta em aprovação, leva os alunos a se martirizarem pelo seu "fracasso" - e perguntamo-nos: fracasso de quem? De um indivíduo? De um curso pré-vestibular? De uma classe social? De um sistema educacional? Sem compreender que os fracassos não são individuais, e sim coletivos, os jovens que não têm seus nomes impressos nas restritas listas de aprovados seguem se culpando, achando que não se dedicaram o suficiente, que não estudaram como "deveriam".

Essas aproximações que pudemos traçar entre os funcionamentos do curso pré-vestibular comunitário em que trabalhamos e dos cursos particulares que conhecemos (e nos quais muitos de nós estudamos) indicam que as práticas que observamos de ajustamento e tutela dos alunos, pautadas em uma ideologia meritocrática, não dizem respeito apenas a uma instituição, e sim revelam um modo de funcionamento presente ao longo de todo o sistema de educação do Brasil, ao qual o vestibular e as instituições criadas em torno dele dão visibilidade, pela importância política que adquirem nos processos de seleção para a universidade. Sustentamos, nesse sentido, que o vestibular funciona como analisador do sistema educacional brasileiro, evidenciando seu funcionamento e revelando os processos de seletividade socioeconômica que estão escondidos sob a aparência de pretensa imparcialidade e neutralidade da educação formal oferecida por uma sociedade que garante direitos iguais para todos, mas apenas na letra da lei.

Acreditamos, então, que a dificuldade de compreensão da proposta da AV pela equipe do pré-vestibular como um todo se deve ao choque, à ruptura trazida pelo novo quando se insere em uma estrutura cristalizada, em que prevalecem modos hegemônicos de se educar e de se fazer psicologia. É importante, nesse ponto, compreender que as concepções críticas no campo da psicologia e da educação não se sobrepuseram aos modelos tradicionais nessas áreas. Embora elas tenham alcançado influência expressiva na mobilização de psicólogos e educadores a partir dos anos 1980, tais práticas não desarticularam os paradigmas tradicionais, prevalentes na época e presentes até hoje em nossas instituições educativas, seja na educação de base, seja no ensino superior, estejam inseridas formalmente no sistema educacional do país ou não, como é o caso dos cursos pré-vestibular.

Embora as práticas críticas ganhem cada vez mais força, encontrando embasamento teórico em pensadores de múltiplas linhas no campo da psicologia e da educação e se materializando na iniciativa de psicólogos-educadores e de educadores comprometidos com uma ação política, elas ainda se embatem com as concepções tradicionais enraizadas no pensamento de múltiplos atores no campo educacional brasileiro. Como indica Antunes (2003), o movimento de mudança nas teorias e práticas educativas e psicológicas é heterogêneo, havendo segmentos que tomam a dianteira do processo, outros que respondem tardiamente e, ainda, setores que resistem, como acontece em qualquer processo histórico. Ainda assim, é inegável que o movimento crítico ganha força na atualidade, buscando encontrar, nos interstícios das relações de poder instituídas, um espaço para a afirmação de novos possíveis.

É essa a proposta da Análise do Vocacional. É essa a luta de psicólogos e educadores brasileiros que compreendem que, diante do cenário de disparidades sociais e econômicas produzidas historicamente no país, suas ações profissionais necessitam incorporar uma dimensão política, que aposte em um movimento de mudança. Não se trata de uma modificação repentina, em uma revolução radical, e sim de um processo micropolítico, em que tais sujeitos se utilizem do poder - que, lembrando Foucault, circula - que Ihes é investido para promover pequenos movimentos de ruptura no que está instituído, cristalizado, abrindo possibilidades de novas configurações no campo da psicologia e da educação, a partir da produção de escolhas que engendrem modos inéditos, singulares, de existência.

\section{Referências}

Aguiar, K. F., \& Rocha, M. L. (2007). Micropolítica e o exercício da pesquisa-intervenção: referenciais e dispositivos em análise. Psicologia: Ciência e Profissão, 27(4), 648-663.

Antunes, M. A. M. (2003). Psicologia e Educação no Brasil: um olhar histórico-crítico. Em M.A.M. Antunes \& M.E.M. Meira (Orgs.), Psicologia Escolar: teorias críticas (pp. 139-168). São Paulo: Casa do Psicólogo.

Antunes, M. A. M. (2005). A Psicologia no Brasil (4a ed.). São Paulo: Unimarco e Educ. 
Bacca, A. M., Pey, M. O., \& Sá, R. S. (2004). Nas pegadas de Foucault: apontamentos para a pesquisa de instituições. Rio de Janeiro: Achiamé.

Barros, R. D. B. (2007). Grupos: afirmação de um simulacro. Porto Alegre: Editora UFRGS.

Barros, L. P., \& Kastrup, V. (2009). Cartografar é acompanhar processos. Em E. Passos \& V. Kastrup, L. Escóssia (Orgs.), Pistas do método da cartografia (pp. 52-75). Porto Alegre: Sulina, p.52-75.

Bicalho, P. P. G., Bartalini, C. P. B., \& Sasso, N. K. (2010). A prática de orientar vocações e os sentidos atuais do trabalho. Liinc em Revista, 6(1), 128-141.

Bicalho, P. P. G., \& Sousa, C. F. (2010). Extensão universitária na formação em psicologia e a questão vocacional: um analisador da produção de subjetividades._Psicologia: Ensino e Formação, 1(2), 35-46.

Bock, A. M. B. (1999). Aventuras do Barão de Münchhausen na psicologia. São Paulo: Cortez Editora.

Bock, S. D. (2010). Orientação profissional para as classes pobres. São Paulo: Cortez Editora.

Deleuze, G. (1996). O que é um dispositivo? Em G. Deleuze, O mistério de Ariana (pp. 83-96). Lisboa: Vega.
Foucault, M. (2008). Vigiar e punir (35a ed.). Petrópolis: Vozes.

Frotté, M. D. (2000). Analítica do Vocacional - Percursos e derivas de uma intervenção. Dissertação de Mestrado, Universidade Federal Fluminense, Niterói-RJ.

Guattari, F., Rolnik, S. (1996). Micropolítica - cartografias do desejo (4a ed.). Petrópolis, RJ: Vozes.

Maciel Junior, A. (2005) O problema da escolha e os impasses na clínica na era do biopoder. Em A. Maciel Junior, D. Kuperman \& S. Tedesco (Orgs.), Polifonias: clínica, política e criação. Rio de Janeiro: Contra-capa.

Mansano, S. R. V. (2003). Trajetória profissional: uma construção artística. Em Vida e profissão: cartografando trajetórias (pp. 6784). São Paulo: Summus.

Patto, M. H. S. (1996). A produção do fracasso escolar. São Paulo: TAQ.

Swartz, D. (1997). Pierre Bourdieu: a transmissão cultural da desigualdade social. Em M. H. S. Patto (Org.), Introdução à Psicologia Escolar (3a ed.) (pp.35-49). São Paulo: Casa do Psicólogo.

Recebido em: 30/05/2011

Aprovado em: 09/04/2012

\section{Sobre os autores}

Ana Luísa de Marsillac Melsert (almelsert@gmail.com)

Psicóloga graduada pela Universidade Federal do Rio de Janeiro, Mestranda do Programa de Estudos Pós-Graduados em Educação: Psicologia da Educação da Pontifícia Universidade Católica de São Paulo. Endereço: Rua Herculano de Freitas, 141/64 - Bela Vista - São Paulo - SP. CEP 01308-020

Pedro Paulo Gastalho de Bicalho (ppbicalho@ufrj.br)

Doutor em Psicologia, Professor do Programa de Pós-Graduação em Psicologia da Universidade Federal do Rio de Janeiro. Endereço: Rua Siqueira Campos, 225/901 - Copacabana - Rio de Janeiro - RJ. CEP 22031-071

Artigo derivado do Trabalho de Conclusão de Curso em Psicologia intitulado "O vestibular como ponto de (des)encontros entre práticas em psicologia e em educação", apresentado à Universidade Federal do Rio de Janeiro em Dezembro de 2010 como requisito parcial para colação de grau de Formação em Psicólogo. 